\title{
Synthesis, Herbicidal Evaluation, and Structure-Activity Relationship of Benzophenone Oxime Ether Derivatives
}

\author{
Jimei Ma, Mingwei Ma, Linhao Sun, Zhen Zeng, and Hong Jiang \\ Department of Chemistry, College of Sciences, Huazhong Agricultural University, Wuhan 430070, China \\ Correspondence should be addressed to Hong Jiang; jianghong0066@126.com
}

Received 30 April 2015; Revised 3 July 2015; Accepted 8 July 2015

Academic Editor: Florent Barbault

Copyright (C) 2015 Jimei Ma et al. This is an open access article distributed under the Creative Commons Attribution License, which permits unrestricted use, distribution, and reproduction in any medium, provided the original work is properly cited.

\begin{abstract}
A novel series of benzophenone oxime ether derivatives with tertiary amine groups were synthesized and their herbicidal activities of 24 compounds against Oryza sativa, Sorghum sudanense, Brassica chinensis, and Amaranthus mangostanus L. were also evaluated. Most of these compounds exhibited significant inhibitory effect on root growth at $20 \mathrm{ppm}$. Based on the herbicidal activity data, computational Three-Dimensional Quantitative Structure-Activity Relationship (3D-QSAR) analysis and molecular docking were undertaken. CoMFA contour maps were generated for the design of benzophenone oxime ether analogues with enhancing activity.
\end{abstract}

\section{Introduction}

Pesticides are extensively used in agriculture and undoubtedly play a pivotal role in retaining high production and quality of crop [1]. Nevertheless, with the escalating demand of environment protection and food safety, the economic, health, and environmental costs of pesticides have to be considered [2]. This requires that pesticides must be selective, effective, of less residue, and safe. On the other hand, most pesticides could lose efficacy due to resistance after long-term usage. Thus, continuous effort has been made to develop new pesticides with broad spectrum, low dosage and cost, long efficacy duration, less environmental pollution, and safety to humans $[3,4]$.

In recent years, oxime ether derivatives exhibit high potential to be developed as pesticides. For example, flucycloxuron is an insect growth regulator and trifloxystrobin has been used as a fungicide. Moreover, various novel oxime ethers have been reported to possess remarkable antibacterial, insecticidal, and fungicidal activities [5-9]. A series of $O$-benzyl oxime ethers containing $\beta$-methoxyacrylate moiety was synthesized by Liu et al. and was found to possess both fungicidal and insecticidal activities $[5,10$, 11]. Kabilan group revealed that oxime ethers derived from 1-allyl substituted 2,6-diphenylpiperidin-4-ones displayed excellent antibacterial and antifungal activity [12]. Zhang et al. demonstrated that 4-methoxybenzaldehyde $O$-(4bromobenzyl) oxime exerted good larvicidal activity against Myzus persicae and its analogues exhibited excellent fungicidal activity against Rhizoctonia solani [13]. Sun et al. reported that some benzoylphenylureas containing an oxime ether group showed excellent larvicidal activities against mosquito and oriental armyworm [6]. Besides, some 2,4-diphenyl-1,3oxazolines containing oxime ether moiety exhibited higher acaricidal activity than etoxazole [2]. A few pyrazole oxime ether derivatives exhibited both good acaricidal and insecticidal activities [14-16]. More recently, a series of benzofuransubstituted oxime ethers were identified to possess good to excellent fungicidal activities by Xie et al. [17, 18].

However, very few results on the herbicidal activities of oxime ether compound were reported [19]. In this paper, a series of aryl oxime ether compounds with tertiary amino groups which are conducive to enhancing environmental compatibility $[17,20]$ were designed and synthesized. The herbicidal activities of these compounds on Oryza sativa, Sorghum sudanense, Brassica chinensis, and Amaranthus mangostanus L. were investigated. Computational ThreeDimensional Quantitative Structure-Activity Relationship (3D-QSAR) analysis and molecular docking were also undertaken. 


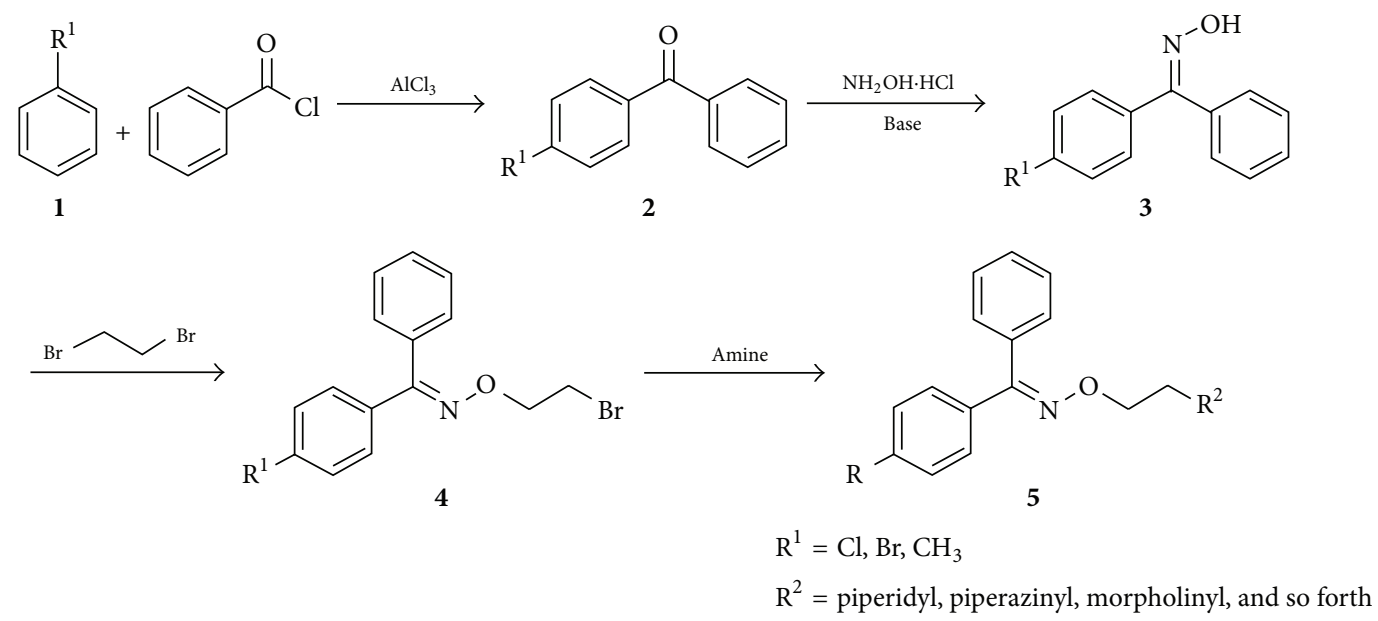

SCHEME 1: The synthetic route to target compounds.

\section{Materials and Methods}

2.1. General. All reagents and solvents (Analytical Reagent grade) were commercially available and used without further purification. Melting points were measured on an RY-2 apparatus. IR spectra were recorded on a Thermo Nicolet FT-IR Avatar 330 instrument with $\mathrm{KBr} .{ }^{1} \mathrm{H}$ NMR spectra were collected at room temperature on $400 \mathrm{MHz}$ Bruker AM, $600 \mathrm{MHz}$ Bruker DRX spectrometers. The residual solvent signals were taken as the reference $\left(7.26 \mathrm{ppm}\right.$ in $\mathrm{CDCl}_{3}$ and $2.50 \mathrm{ppm}$ in $d_{6}$-DMSO). Chemical shift $(\delta)$ is reported in ppm; coupling constants $(J)$ are given in $\mathrm{Hz}$. The following abbreviations classify the multiplicity: $s=$ singlet, $\mathrm{d}=$ doublet, $\mathrm{t}=$ triplet, and $\mathrm{m}=$ multiplet or unresolved. MS (ESI) spectra were recorded on Agilent 6100 Single Quad spectrometer.

2.2. Chemical Synthesis. Aryl ketone was prepared from substituted benzene and arylcarboxylic chloride through Friedel-Crafts reaction. Reaction of ketone with hydroxylamine hydrochloride in the presence of base would result in corresponding oxime, which converted to substituted benzophenone-O-(2-bromoethyl) oxime. Finally, the target products could be obtained by substitution (Scheme 1).

2.2.1. General Procedure for the Synthesis of Substituted Benzophenones. Benzoyl chloride $(0.12 \mathrm{~mol})$ was added dropwise to a mixture of substituted benzene $(0.1 \mathrm{~mol})$ and $\mathrm{AlCl}_{3}$ $(0.12 \mathrm{~mol})$ at room temperature. After complete addition, the mixture was refluxed for another $6 \mathrm{~h}$. Then, the reaction was quenched with ice-water and extracted with chloroform $(3 \times$ $30 \mathrm{~mL}$ ). The combined organic phase was washed with water, $\mathrm{Na}_{2} \mathrm{CO}_{3}$ solution, and brine successively, dried over $\mathrm{MgSO}_{4}$, filtered, and evaporated. The crude product was used directly for next step without any further purification.

2.2.2. General Procedure for the Synthesis of Substituted Benzophenone Oximes. Aqueous $\mathrm{NaOH}$ solution $(10 \mathrm{~mL}$, $20 \mathrm{M}$ ) was added to a mixture of substituted benzophenone $(0.05 \mathrm{~mol})$ and hydroxylamine hydrochloride $(0.1 \mathrm{~mol})$ in ethanol $(50 \mathrm{~mL})$ at room temperature. Then, the reaction was heated to $75^{\circ} \mathrm{C}$ and stirred until the starting material was completely consumed as indicated by TLC. The mixture was cooled to room temperature and filtered. The filtrate was evaporated and dissolved in chloroform, washed with water. The crude compound was recrystallized by ethanol to give a white solid [21].

2.2.3. General Procedure for the Synthesis of Substituted Benzophenone-O-(2-bromoethyl) Oxime. Aqueous $\mathrm{NaOH}$ solution $(10 \mathrm{~mL}, 25 \mathrm{M})$ was added to a mixture of substituted benzophenone oxime $(0.025 \mathrm{~mol}), 1,2$-dibromoethane $(0.03 \mathrm{~mol})$, and tert-butylammonium bromide $(0.2 \mathrm{~g})$ in toluene $(20 \mathrm{~mL})$. The mixture was stirred at room temperature and monitored by TLC. After the reaction was completed, the resulting solution was separated. The organic phase was washed with water until neutral, dried over $\mathrm{MgSO}_{4}$, and filtered. The filtrate was evaporated and purified by column chromatography on silica gel to give substituted benzophenone-O-(2-bromoethyl) oxime [22].

2.2.4. General Procedure for the Synthesis of Target Compounds. A mixture of substituted benzophenone-O-(2-bromoethyl) oxime $(0.01 \mathrm{~mol})$, amine $(0.012 \mathrm{~mol})$, and $\mathrm{Na}_{2} \mathrm{CO}_{3}$ $(0.01 \mathrm{~mol})$ in acetone $(20 \mathrm{~mL})$ was stirred at room temperature. The reaction was monitored by TLC. After the reaction was completed, the resulting suspension was filtered. The filtrate was evaporated to remove acetone and the residue was dissolved in EtOAc $(20 \mathrm{~mL})$, washed with water, dried over $\mathrm{MgSO}_{4}$, filtered, and evaporated. The crude product was purified by column chromatography on silica gel [23]. The unreacted substituted benzophenone-O-(2-bromoethyl) oxime was removed by $\mathrm{Et}_{2} \mathrm{O} /$ petroleum ether $=1: 10$. The final products (Table 1) were obtained by eluting with the indicated solvent. The characterization of compounds $5 \mathbf{a}-$ $\mathbf{5 x}$ was included in the Supporting Information in Supplementary Material available online at http://dx.doi.org/10.1155/ 2015/435219. 
TABLE 1: Chemical structure of the target compounds $\mathbf{5 a}-\mathbf{5 x}$.

\begin{tabular}{|c|c|c|c|c|c|c|}
\hline Compound & $\mathrm{R}^{1}$ & $\mathrm{R}^{2}$ & Compound & $\mathrm{R}^{1}$ & $\mathrm{R}^{2}$ & \\
\hline $5 \mathbf{a}$ & $p-\mathrm{Cl}$ & $-\mathrm{N}\left(\mathrm{CH}_{2} \mathrm{CH}_{2} \mathrm{CH}_{3}\right)_{2}$ & $5 \mathrm{~m}$ & p-Me & & \\
\hline $5 \mathbf{b}$ & $p-\mathrm{Cl}$ & $-\mathrm{N}\left(\mathrm{CH}_{2} \mathrm{CH}_{2} \mathrm{CH}_{2} \mathrm{CH}_{3}\right)_{2}$ & $5 n$ & $p-\mathrm{Cl}$ & & \\
\hline $5 c$ & $p-\mathrm{Me}$ & $-\mathrm{N}\left(\mathrm{CH}_{2} \mathrm{CH}_{2} \mathrm{CH}_{3}\right)_{2}$ & 50 & $p-\mathrm{Me}$ & & \\
\hline $5 d$ & $p-\mathrm{Me}$ & $-\mathrm{N}\left(\mathrm{CH}_{2} \mathrm{CH}_{2} \mathrm{CH}_{2} \mathrm{CH}_{3}\right)_{2}$ & $5 p$ & $p-\mathrm{Cl}$ & & \\
\hline $5 e$ & $p$-Me & & $5 q$ & $p-\mathrm{Br}$ & & \\
\hline $5 f$ & $p-\mathrm{Cl}$ & & $5 r$ & $p-\mathrm{Me}$ & & \\
\hline $5 \mathrm{~g}$ & $p-\mathrm{Br}$ & & $5 s$ & $p-\mathrm{Cl}$ & & \\
\hline $5 \mathrm{~h}$ & $o-\mathrm{Cl}$ & & $5 t$ & $p-\mathrm{Br}$ & & \\
\hline $5 i$ & $p-\mathrm{NO}_{2}$ & & $5 u$ & $p-\mathrm{Cl}$ & & \\
\hline $5 \mathbf{j}$ & $p-\mathrm{Cl}$ & & $5 v$ & $p-\mathrm{Br}$ & & \\
\hline $5 k$ & $p-\mathrm{Br}$ & & $5 w$ & $p-\mathrm{Cl}$ & & \\
\hline 51 & $p-\mathrm{Cl}$ & & $5 x$ & $p-\mathrm{Br}$ & & \\
\hline
\end{tabular}

See Scheme 2.<smiles>[R]CCON=C(c1ccccc1)c1ccccc1</smiles>

SCHEME 2

2.3. Biological Testing. The in vivo herbicidal activities of compounds $\mathbf{5} \mathbf{a}-\mathbf{5} \mathbf{x}$ against monocotyledon (Oryza sativa, Sorghum sudanense) and dicotyledon (Brassica chinensis, Amaranthus mangostanus L.) were examined according to the plating method in agricultural industry standard of China pesticide indoor bioassay test criteria (herbicide) (NY/T 1155.1, 2006).

The weeds were soaked in $25^{\circ} \mathrm{C}$ water for $12 \mathrm{~h}$ and then transferred to moist gauze, which was put in manual climatic box at $28^{\circ} \mathrm{C}$ to germinate. $0.12 \mathrm{~g}$ of the target compounds 
was diluted with $3 \mathrm{~mL}$ DMF. $0.5 \mathrm{~mL}$ of the diluted solution was diluted to $100 \mathrm{~mL}$ with $0.1 \%$ aqueous Tween- 80 solution to prepare a mother solution $(200 \mathrm{~g} / \mathrm{L})$. The test solutions were then prepared by diluting suitable mother solution to $100 \mathrm{~mL}$ with $0.1 \%$ aqueous Tween- 80 solution. 10 germinating seeds were selected and put in the Petri dish matted with a filtered paper, to which $9 \mathrm{~mL}$ of testing solution was added. $0.1 \%$ aqueous Tween- 80 solution was used as blank control. The Petri dishes were put in manual climatic box setting temperature as $25^{\circ} \mathrm{C}$ and humidity as $98 \%$ in dark condition. The root length was measured after 5 days and the inhibitory rate was calculated with the following equation. All the samples were repeated for 3 times. The abnormal data was got rid of by SPSS19.0. Consider

$$
R=\frac{L_{0}-L_{1}}{L_{0}} \times 100 .
$$

$R$ is growth inhibitory rate (\%); $L_{0}$ is the root length of control; $L_{1}$ is the root length of testing sample.

A coordinate plot was built with concentration as $X$ axial and inhibitory rate as $Y$ axial. Linear fitting was processed for each compound to give the univariate linear regression equation (the correlation data was attached in the supporting information). $\mathrm{IC}_{90}$ was calculated by the linear equation. $\mathrm{pIC}_{90}$ was the value of $\log \mathrm{IC}_{90}$.

2.4. Molecular Modeling. The analysis is based on SYBYL 7.3 (Tripos Inc., USA). A training set of 19 compounds was used to construct the $3 \mathrm{D}-\mathrm{QSAR}$ models. Considering the distribution of the structural diversity, 5 compounds were randomly selected as prediction test set to evaluate the obtained 3D-QSAR model.

Since the acceptor is unknown, the low energy conformation was chosen as the active conformation [24, 25]. Molecules are minimized by Tripos force field and the Powell conjugate gradient algorithm with a convergence criterion of $0.05 \mathrm{kcal} /(\mathrm{mol} \AA)$ to give the low energy conformation, and then all compounds were aligned by Database Alignment method. Compound 5k was selected as template molecule [26]. Other molecules are overlapped to reduce the rootmean-square derivation. The common skeleton was shown in Figure 1.

The composite data and $\mathrm{pIC}_{90}$ data were imported to calculate the CoMFA field parameters by Tripos Standard force field (the steric and electrostatic field). Default parameters such as dielectric constant were used to obtain the molecular force parameters $[27,28]$. Partial Least-Square (PLS) methodology was employed to construct the relationships between the target compound and biological activity. The leave-oneout (LOO) cross-validation was performed to obtain the cross-validation correlation coefficient $\left(q^{2}\right)$ and the optimum number of components ( $n)$. A non-cross-validated (NV) analysis was carried out to obtain the non-cross-validated correlation coefficient $\left(r^{2}\right)$ and $F$ test values and standard error of estimate (SEE).

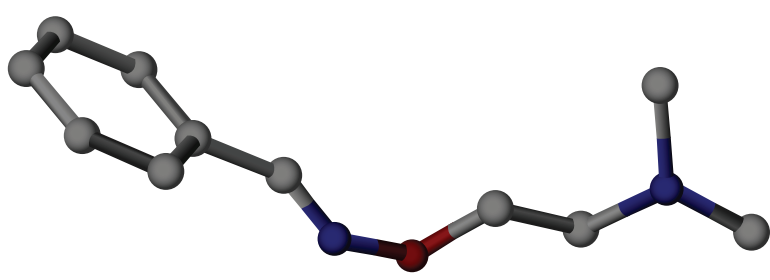

FIGURE 1: Common skeleton of target compounds.

\section{Results and Discussion}

3.1. Herbicidal Activity Evaluation. After a preliminary study, the concentration of testing compounds was set as $1,2.5,5$, 10,20 , and $40 \mathrm{mg} / \mathrm{L}$ in the herbicidal activity investigation. The root growth was observed and the collected data was analyzed by SPSS to calculate the inhibitory rate. The results showed that the inhibitory effect became stronger as the concentration was increased and most of these compounds' inhibitory rates were up to $80 \%$ above at $20 \mathrm{mg} / \mathrm{L}$ (see Supporting Information). It indicated that these oxime ether compounds with tertiary amines significantly inhibited the crop root growth, which is another example to support the point that nitrogen functional groups are significant for the biological activity in most agrochemicals [29]. IC I0 $_{90}$ the concentration inhibiting $90 \%$ of activity, was calculated according to the correlation analysis between the inhibitory rate on root growth and the concentration of the testing solution (see Supporting Information). Compound $\mathbf{5 f}$ exhibited the best herbicidal activity against Oryza sativa with an $\mathrm{IC}_{90}$ of $13.70 \mathrm{mg} / \mathrm{L}$. Compound 50 effectively inhibited the root growth of Sorghum sudanense with an $\mathrm{IC}_{90}$ of $11.27 \mathrm{mg} / \mathrm{L}$. Compounds 5k and 5i showed the highest herbicidal activity against Brassica chinensis and Amaranthus mangostanus L. with an $\mathrm{IC}_{90}$ of 16.83 and $11.22 \mathrm{mg} / \mathrm{L}$, respectively. The herbicidal activities of these compounds are comparable to those of tribenuron, which is a commonly used commercial herbicide [30] (Table 2).

It was noteworthy that the benzophenone oxime ethers containing piperidine or piperazine moiety $(5 \mathbf{e}-\mathbf{5 0})$ showed significant inhibitory activities. Increase of the concentration of these kinds of compounds to $20 \mathrm{mg} / \mathrm{L}$ caused plants' fatality. The compounds containing oxygen atom on amino moiety (5p-5r) show less inhibitory effect than that of those without oxygen (5a-5o). In particular, incremental carboxylic acid group on piperidine ring (5s-5x) strongly reduced the herbicidal activities. The inhibitory effects of the testing compound on Oryza sativa were generally stronger than those of Sorghum sudanense in terms of monocotyledon, while the inhibitory effects on Amaranthus mangostanus L. were better than those of Brassica chinensis as for dicotyledon.

3.2. Comparative Molecular Field Analysis (CoMFA). The CoMFA analysis results for Oryza sativa and Amaranthus mangostanus L. were listed in Table 3. The activities data of Sorghum sudanense and Brassica chinensis did not show satisfactory regularity and CoMFA model was not analyzed. 
TABLE 2: Calculated $\mathrm{IC}_{90}$ of compounds $\mathbf{5} \mathbf{a}-\mathbf{5} \mathbf{x}$.

\begin{tabular}{|c|c|c|c|c|}
\hline \multirow{2}{*}{ Compound } & \multicolumn{4}{|c|}{$\mathrm{IC}_{90}$} \\
\hline & Oryza sativa & Sorghum sudanense & Brassica chinensis & Amaranthus mangostanus L. \\
\hline Tribenuron & 12.28 & 13.70 & 11.89 & 11.06 \\
\hline $5 a$ & 21.11 & 33.55 & 25.28 & 12.71 \\
\hline $5 \mathbf{b}$ & 21.09 & 26.55 & 43.81 & 22.14 \\
\hline $5 \mathrm{c}$ & 42.04 & 17.81 & 35.72 & 17.96 \\
\hline $5 d$ & 44.92 & 34.27 & 68.52 & 31.56 \\
\hline $5 e$ & 14.85 & 60.06 & 33.92 & 18.38 \\
\hline $5 f$ & 13.70 & 48.10 & 32.73 & 34.01 \\
\hline $5 g$ & 34.19 & 55.20 & 32.17 & 17.32 \\
\hline $5 \mathrm{~h}$ & 52.88 & 36.42 & 52.34 & 25.51 \\
\hline $5 i$ & 24.79 & 17.23 & 28.02 & 11.22 \\
\hline $5 \mathbf{j}$ & 20.13 & 25.54 & 22.84 & 16.83 \\
\hline $5 k$ & 18.11 & 20.65 & 16.83 & 11.72 \\
\hline 51 & 20.55 & 35.74 & 17.21 & 15.70 \\
\hline $5 \mathrm{~m}$ & 21.28 & 36.87 & 48.70 & 17.69 \\
\hline $5 n$ & 17.47 & 21.52 & 87.47 & 19.22 \\
\hline 50 & 20.44 & 11.27 & 23.67 & 14.67 \\
\hline $5 p$ & 56.79 & 55.64 & 97.02 & 46.68 \\
\hline $5 q$ & 102.32 & 52.96 & 146.21 & 50.55 \\
\hline $5 r$ & 72.32 & 244.24 & 439.01 & 53.68 \\
\hline $5 s$ & 107.40 & 39.85 & 68.15 & 43.25 \\
\hline $5 t$ & 106.86 & 387.23 & 134.91 & 139.05 \\
\hline $5 u$ & 67.62 & 194.54 & 108.17 & 203.32 \\
\hline $5 v$ & 90.00 & 733.00 & 140.28 & 115.99 \\
\hline $5 w$ & 89.43 & 121.02 & 130.27 & 216.57 \\
\hline $5 x$ & 121.02 & 133.36 & 147.23 & 379.80 \\
\hline
\end{tabular}

TABLE 3: Summary of CoMFA results.

\begin{tabular}{lcccccrr}
\hline \multirow{2}{*}{ Fields } & \multicolumn{3}{c}{ LOO } & \multicolumn{2}{c}{ NV } & Steric & Electrostatic \\
& $q^{2}$ & $n$ & $r^{2}$ & SEE & $F$ & 0.446 & 0.554 \\
Oryza sativa & 0.567 & 2 & 0.997 & 0.020 & 751.322 & 0.481 & 0.519 \\
Amaranthus mangostanus L. & 0.621 & 3 & 0.879 & 0.185 & 53.325 & 0.96 \\
\hline
\end{tabular}

The CoMFA model for Oryza sativa has a $q^{2}$ value of 0.567 and $r^{2}$ value of 0.997 . It has an $F$ value of 751.322 and an SEE value of 0.020 . The CoMFA model for Amaranthus mangostanus L. has a $q^{2}$ value of 0.621 and $r^{2}$ value of 0.879 . It has an $F$ value of 53.325 and an SEE value of 0.185 . According to the literature [31], the $q^{2}\left(q^{2}>0.5\right)$ and $r^{2}$ $\left(r^{2}>0.6\right)$ values illustrated that the resulted models have good robustness and internal prediction ability. Both models revealed that the electrostatic field $(55.4 \%, 51.9 \%)$ has a little bit more contribution than that of steric fields $(44.6 \%, 48.1 \%)$. This indicated that the electronic effect of testing compounds structure has more influence on the inhibitory activities against the plants' roots.

The 3D-QSAR models established with the training set were further validated with the test set. The CoMFA model gave reasonable predictions of both training and test set compounds. The experimental activity and predicted activity of the compounds and their residuals are listed in Tables 4 and 5 . In both models, most of the predicted $\mathrm{pIC}_{90}$ values are pretty close to the corresponding experimental values. All the deviations are smaller than $1 \log$ unit and the maximum deviation is only 0.321 .

3.3. Contour Map Analysis. The 3D contour maps were generated as scalar products of coefficients and standard deviation associated with each CoMFA. The active compound 5k was superimposed with the CoMFA contour maps for Oryza sativa and Amaranthus mangostanus L.

In Figure 2, yellow region near benzene ring shows that substituents at this position have unfavorable steric interaction. This is verified by the observation that compound $5 \mathbf{h}$ with $o-\mathrm{Cl}$ on benzene exhibited less inhibition than that of 5f with $p$-Cl. Blue region below the chain especially around the amino groups indicates that electronegative groups are unfavored in this region. This is rightly explained by the fact that compounds $\mathbf{5 s - 5 x}$ with extra carboxylic acid group 
TABLE 4: Observed and predicted activities for training and test set of Oryza sativa CoMFA model.

\begin{tabular}{|c|c|c|c|}
\hline \multirow{2}{*}{ Compound } & \multicolumn{3}{|c|}{$\mathrm{pIC}_{90}$} \\
\hline & Observed & Predicted & Residual \\
\hline $5 a$ & 1.32 & 1.345 & -0.025 \\
\hline $5 b$ & 1.32 & 1.311 & 0.009 \\
\hline $5 c$ & 1.62 & 1.600 & 0.020 \\
\hline $5 d^{*}$ & 1.65 & 1.591 & 0.059 \\
\hline $5 e$ & 1.17 & 1.207 & -0.037 \\
\hline $5 f$ & 1.14 & 1.158 & -0.018 \\
\hline $5 g^{*}$ & 1.53 & 1.558 & -0.028 \\
\hline $5 \mathrm{~h}$ & 1.72 & 1.716 & 0.004 \\
\hline $5 i$ & 1.39 & 1.361 & 0.029 \\
\hline $5 \mathbf{j}$ & 1.30 & 1.326 & -0.026 \\
\hline $5 \mathrm{k}$ & 1.26 & 1.248 & 0.012 \\
\hline 51 & 1.31 & 1.274 & 0.036 \\
\hline $5 \mathrm{~m}^{*}$ & 1.33 & 1.352 & -0.022 \\
\hline $5 n$ & 1.24 & 1.259 & 0.019 \\
\hline 50 & 1.31 & 1.511 & -0.201 \\
\hline $5 p^{*}$ & 1.75 & 1.746 & 0.004 \\
\hline $5 q$ & 2.01 & 1.992 & 0.018 \\
\hline $5 r$ & 1.86 & 2.156 & -0.296 \\
\hline $5 s^{*}$ & 2.03 & 2.056 & -0.026 \\
\hline $5 t$ & 2.03 & 2.019 & 0.011 \\
\hline $5 u$ & 1.83 & 1.807 & 0.023 \\
\hline $5 v$ & 1.95 & 1.943 & 0.007 \\
\hline $5 w$ & 1.95 & 1.921 & 0.029 \\
\hline $5 x$ & 2.08 & 2.103 & -0.023 \\
\hline
\end{tabular}

The compound marked with $*$ was selected for test set.

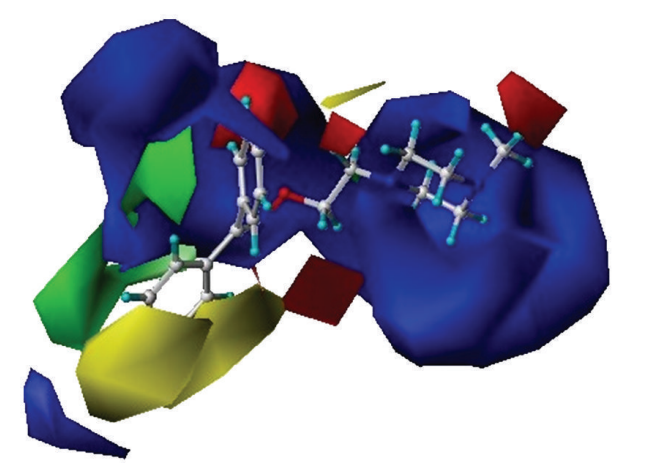

20.000

80.000

FIgURE 2: CoMFA contour map for Oryza sativa.

showed worse inhibitory effect than those of $\mathbf{5 f}$ and $\mathbf{5 g}$. The inhibitory activity on Oryza sativa may increase if electronpositive groups were introduced.

In Figure 3, green region near benzene ring and blue region near amino groups manifested that increasing the size of substituent on benzene ring and importing electronpositive group on tertiary amino part are beneficial for
TABLE 5: Observed and predicted activities for training and test set of Amaranthus mangostanus L. CoMFA model.

\begin{tabular}{|c|c|c|c|}
\hline \multirow{2}{*}{ Compound } & \multicolumn{3}{|c|}{$\mathrm{pIC}_{90}$} \\
\hline & Observed & Predicted & Residual \\
\hline $5 a$ & 1.10 & 1.414 & -0.314 \\
\hline $5 b$ & 1.35 & 1.307 & 0.043 \\
\hline $5 c$ & 1.25 & 1.110 & 0.140 \\
\hline $5 d^{*}$ & 1.50 & 1.456 & 0.044 \\
\hline $5 e$ & 1.26 & 1.268 & -0.008 \\
\hline $5 f^{*}$ & 1.53 & 1.539 & -0.009 \\
\hline $5 g$ & 1.24 & 1.261 & -0.021 \\
\hline $5 \mathrm{~h}$ & 1.41 & 1.313 & 0.097 \\
\hline $5 i$ & 1.05 & 1.199 & -0.149 \\
\hline $5 \mathbf{j}^{*}$ & 1.23 & 1.059 & 0.171 \\
\hline $5 k$ & 1.07 & 1.065 & 0.005 \\
\hline 51 & 1.20 & 1.004 & -0.196 \\
\hline $5 \mathrm{~m}$ & 1.25 & 0.971 & -0.279 \\
\hline $5 n$ & 1.28 & 1.083 & 0.197 \\
\hline $5 o^{*}$ & 1.17 & 1.075 & 0.095 \\
\hline $5 p$ & 1.67 & 1.775 & -0.105 \\
\hline $5 q$ & 1.70 & 1.402 & 0.298 \\
\hline $5 r$ & 1.73 & 1.409 & 0.321 \\
\hline $5 s$ & 1.64 & 1.891 & -0.251 \\
\hline $5 t$ & 2.14 & 1.904 & 0.236 \\
\hline $5 u^{*}$ & 2.31 & 2.134 & 0.176 \\
\hline $5 v$ & 2.06 & 2.165 & -0.105 \\
\hline $5 w$ & 2.34 & 2.461 & -0.121 \\
\hline $5 x$ & 2.58 & 2.480 & 0.10 \\
\hline
\end{tabular}

The compound marked with $*$ was selected for test set.

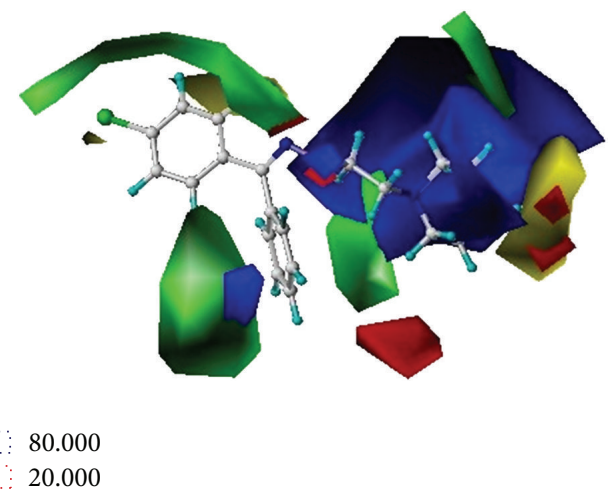

FIGURE 3: CoMFA contour map for Amaranthus mangostanus L.

enhancing the inhibitory effect on Amaranthus mangostanus L. Actually, compounds 5a-5o showed stronger inhibitory effect than that of $\mathbf{5 p}-\mathbf{5 r}$ with morpholine tail and $\mathbf{5 s}-\mathbf{5 x}$ with carboxylic acid on piperidine ring.

On the whole, the structural insights obtained from molecular docking and 3D-QSAR contour maps are consistent with the experimental data, indicating that the molecular docking and the developed 3D-QSAR models are reliable to some extent. The 3D-QSAR contour maps show that the 
electronic effect contributes to the strong herbicidal activity. Introduction of electron-positive group to the amino group of the test compounds may facilitate improving the inhibitory effect on Oryza sativa and Amaranthus mangostanus.

\section{Conclusions}

A series of benzophenone oxime ether derivatives with tertiary amines were synthesized and characterized. These compounds exhibited good herbicidal activities to both monocotyledon and dicotyledon. Based on the experimental results, the combined 3D-QSAR modeling and molecular docking analysis was performed with the data of Oryza sativa and Amaranthus mangostanus L. Due to the insufficient compounds structure diversity and variable influence factor, the models were assumed to be predictive but not perfectly reliable. However, these results threw a light on the research and development on the oxime ethers with amino groups to be herbicides.

\section{Conflict of Interests}

The authors declare that there is no conflict of interests regarding the publication of this paper.

\section{Authors' Contribution}

Jimei Ma and Mingwei Ma contributed equally to this paper.

\section{Acknowledgment}

The financial support (Program nos. 2013PY121 and 2012BQ029) provided by the Fundamental Research Funds for the Central Universities, China, is gratefully acknowledged.

\section{References}

[1] A. S. Felsot and K. D. Racke, "Chemical pest control technology: benefits, disadvantages, and continuing roles in crop production systems," ACS Symposium Series, vol. 947, pp. 1-18, 2007.

[2] Y. Li, C. Li, Y. Zheng et al., "Design, synthesis, acaricidal activity, and mechanism of oxazoline derivatives containing an oxime ether moiety," Journal of Agricultural and Food Chemistry, vol. 62, no. 14, pp. 3064-3072, 2014.

[3] Y. Xiang, M. Wang, X. Sun, D. Cai, and Z. Wu, "Controlling pesticide loss through nanonetworks," ACS Sustainable Chemistry \& Engineering, vol. 2, no. 4, pp. 918-924, 2014.

[4] C. Liu, A. Guan, J. Yang et al., "Efficient approach to discover novel agrochemical candidates: intermediate derivatization method," Journal of Agricultural and Food Chemistry, 2015.

[5] Z.-B. Hu, H.-A. Luo, X.-G. Wang et al., "Synthesis and evaluation O-benzyl oxime-ether derivatives containing $\beta$ methoxyacrylate moiety for insecticidal and fungicidal activities," Bulletin of the Korean Chemical Society, vol. 35, no. 4, pp. 1073-1076, 2014.

[6] R. Sun, M. Lü, L. Chen et al., "Design, synthesis, bioactivity, and structure-activity relationship (SAR) studies of novel benzoylphenylureas containing oxime ether group," Journal of
Agricultural and Food Chemistry, vol. 56, no. 23, pp. 11376-11391, 2008.

[7] W.-D. Liu, S.-L. Lan, Z.-L. Lan, and X.-G. Wang, "Synthesis and bioactivity of $\mathrm{N}$-methoxylcarbamates containing methylthio and oxime ether group," Chinese Journal of Organic Chemistry, vol. 26, no. 8, pp. 1115-1119, 2006.

[8] B.-A. Song, X.-H. Liu, S. Yang, D.-Y. Hu, L.-H. Jin, and Y.-T. Zhang, "Recent advance in synthesis and biological activity of oxime," Chinese Journal of Organic Chemistry, vol. 25, no. 5, pp. 507-525, 2005.

[9] M. N. Soltani Rad, S. Behrouz, E. Zarenezhad et al., "Synthesis of fluorene and/or benzophenone O-oxime ethers containing amino acid residues and study of their cardiovascular and antibacterial effects," Medicinal Chemistry Research, vol. 23, no. 8, pp. 3810-3822, 2014.

[10] A. Liu, X. Wang, C. Chen et al., "The discovery of HNPC-A3066: a novel strobilurin acaricide," Pest Management Science, vol. 65, no. 3, pp. 229-234, 2009.

[11] A. Liu, X. Ou, M. Huang et al., "Synthesis and insecticidal activities of novel oxime ether pyrethroids," Pest Management Science, vol. 61, no. 2, pp. 166-170, 2005.

[12] K. Narayanan, M. Shanmugam, S. Jothivel, and S. Kabilan, "Design, synthesis, spectral and biological evaluation of novel 1-allyl substituted 2,6-diphenylpiperidin-4-ones and its derivatives of oximes/oxime ethers," Bioorganic \& Medicinal Chemistry Letters, vol. 22, no. 21, pp. 6602-6607, 2012.

[13] T. Zhang, R. Xie, T. Zhang, X. Mei, J. Yang, and J. Ning, "Design, synthesis and bioactivities of novel oxime ether derivatives," Journal of Pesticide Science, vol. 38, no. 2, pp. 88-90, 2013.

[14] C. Fu, J. Pei, Y. Ning et al., "Synthesis and insecticidal activities of novel pyrazole oxime ether derivatives with different substituted pyridyl rings," Pest Management Science, vol. 70, no. 8, pp. 1207-1214, 2014.

[15] H. Dai, J. Liu, W. Miao et al., "Synthesis and biological activities of novel pyrazole oxime ether derivatives containing pyridyl ring," Chinese Journal of Organic Chemistry, vol. 31, no. 10, pp. 1662-1667, 2011.

[16] H. Song, Y. Liu, L. Xiong, Y. Li, N. Yang, and Q. Wang, "Design, synthesis, and insecticidal evaluation of new pyrazole derivatives containing imine, oxime ether, oxime ester, and dihydroisoxazoline groups based on the inhibitor binding pocket of respiratory complex I," Journal of Agricultural and Food Chemistry, vol. 61, no. 37, pp. 8730-8736, 2013.

[17] Y.-Q. Xie, Z.-L. Huang, H.-D. Yan et al., "Design, synthesis, and biological activity of oxime ether strobilurin derivatives containing indole moiety as novel fungicide," Chemical Biology \& Drug Design, vol. 85, no. 6, pp. 743-755, 2015.

[18] Y.-Q. Xie, Y.-B. Huang, J.-S. Liu et al., "Design, synthesis and structure-activity relationship of novel oxime ether strobilurin derivatives containing substituted benzofurans," Pest Management Science, vol. 71, no. 3, pp. 404-414, 2015.

[19] L. Jiang, C. Chen, Y. Zhou, Q. Chen, and G. Yang, "Synthesis and herbicidal activities of novel 1,2,4-triazolo[1,5-a]-pyrimidine containing oxime ether moiety," Chinese Journal of Organic Chemistry, vol. 29, no. 9, pp. 1392-1404, 2009.

[20] P. Jeschke and R. Nauen, "Neonicotinoids-from zero to hero in insecticide chemistry," Pest Management Science, vol. 64, no. 11, pp. 1084-1098, 2008.

[21] A. Lachman, "Benzophenone oxime," Organic Syntheses, vol. 2, p. 70,1930 . 
[22] B. C. Askew, C. J. McIntyre, C. A. Hunt et al., "Non-peptide glycoprotein IIb/IIIa inhibitors. 6. Design and synthesis of rigid, centrally constrained non-peptide fibrinogen receptor antagonists," Bioorganic \& Medicinal Chemistry Letters, vol. 5, no. 5, pp. 475-480, 1995.

[23] M. N. S. Rad, S. Behrouz, A. R. Nekoei, Z. Faghih, and A. Khalafi-Nezhad, "Three-component synthesis of some novel $\mathrm{N}$ heterocycle methyl-O-oxime ethers," Synthesis, no. 24, Article ID Z79811SS, pp. 4068-4076, 2011.

[24] M. Clark, R. D. Cramer, and N. Van Opdenbosch, "Validation of the general purpose tripos 5.2 force field," Journal of Computational Chemistry, vol. 10, no. 8, pp. 982-1012, 1989.

[25] A. Liu, L. Hu, X. Liu et al., "3D-QSAR study on insecticidal novel oxime-ether pyrethroids against mythimna separate," Computers and Applied Chemistry, vol. 22, no. 10, pp. 863-866, 2005.

[26] S. J. Cho and A. Tropsha, "Cross-validated R2-guided region selection for comparative molecular field analysis: a simple method to achieve consistent results," Journal of Medicinal Chemistry, vol. 38, no. 7, pp. 1060-1066, 1995.

[27] A. Pick, H. Müller, and M. Wiese, "Structure-activity relationships of new inhibitors of breast cancer resistance protein (ABCG2)," Bioorganic \& Medicinal Chemistry, vol. 16, no. 17, pp. 8224-8236, 2008.

[28] H. Peng, T. Wang, P. Xie, T. Chen, H.-W. He, and J. Wan, "Molecular docking and three-dimensional quantitative structureactivity relationship studies on the binding modes of herbicidal 1-(substituted phenoxyacetoxy)alkylphosphonates to the E1 component of pyruvate dehydrogenase," Journal of Agricultural and Food Chemistry, vol. 55, no. 5, pp. 1871-1880, 2007.

[29] C. Lamberth, "Heterocyclic chemistry in crop protection," Pest Management Science, vol. 69, no. 10, pp. 1106-1114, 2013.

[30] N.-X. Wang, Q. Tang, G.-M. Ai et al., "Biodegradation of tribenuron methyl that is mediated by microbial acidohydrolysis at cell-soil interface," Chemosphere, vol. 86, no. 11, pp. 1098-1105, 2012.

[31] A. Tropsha, P. Gramatica, and V. K. Gombar, "The importance of being earnest: validation is the absolute essential for successful application and interpretation of QSPR models," QSAR and Combinatorial Science, vol. 22, no. 1, pp. 69-77, 2003. 

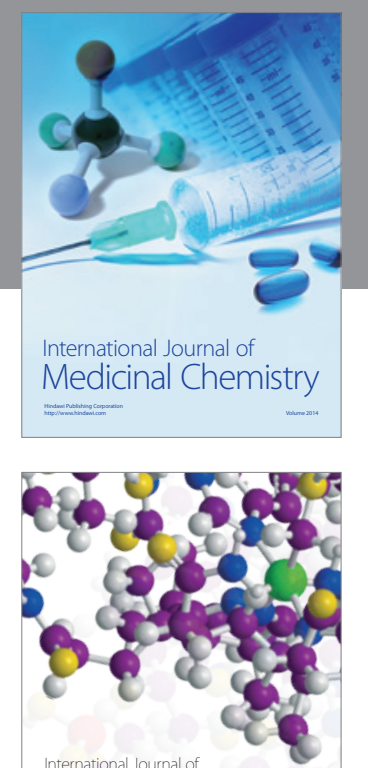

\section{Carbohydrate} Chemistry

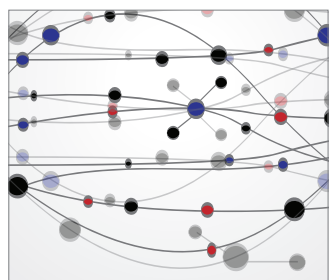

The Scientific World Journal
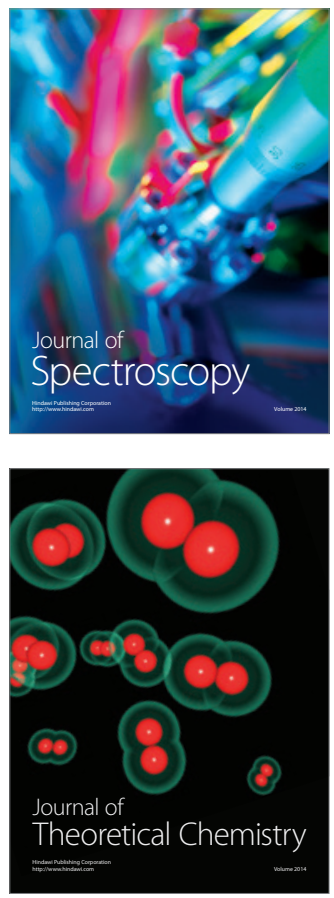
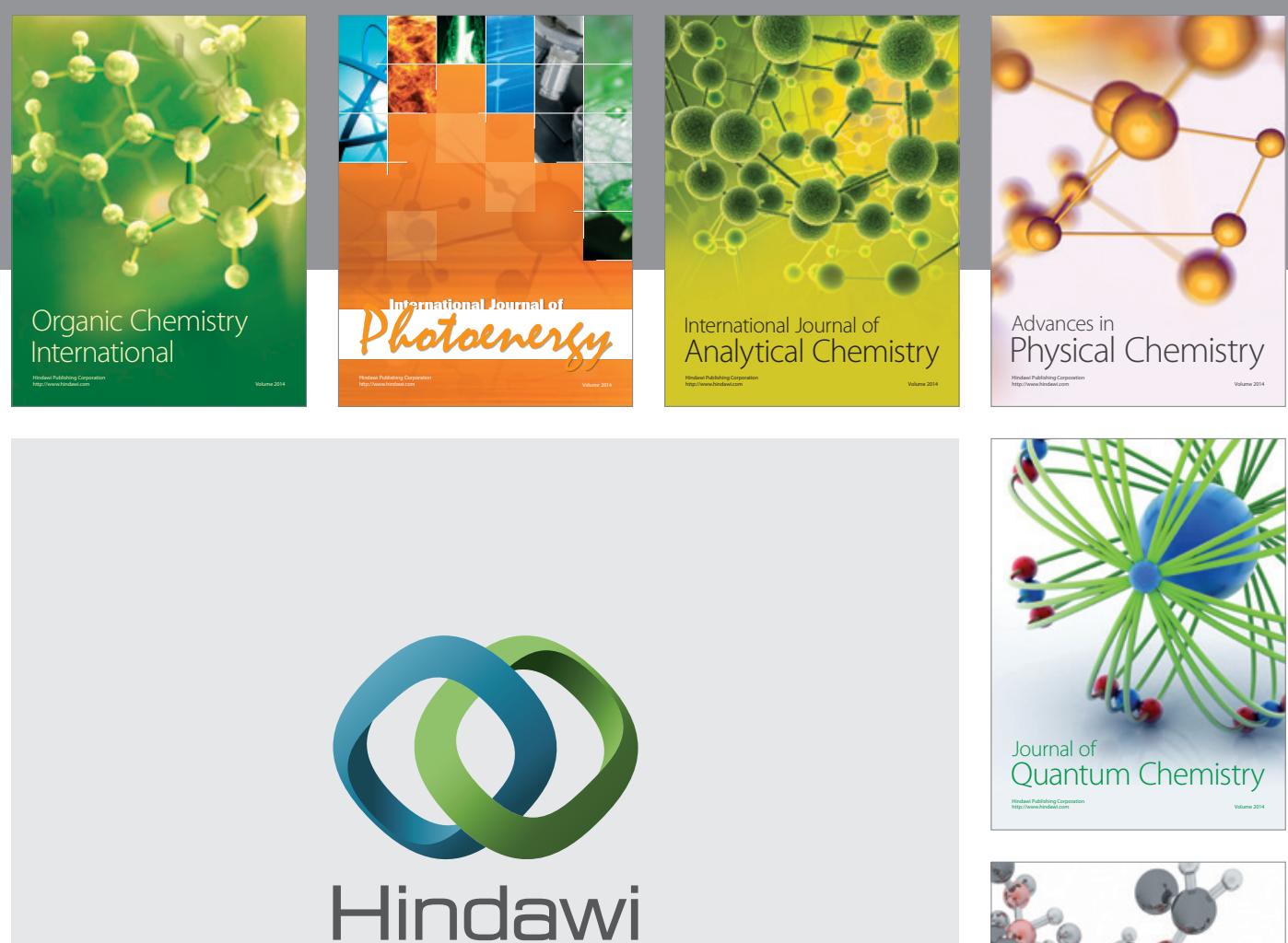

Submit your manuscripts at

http://www.hindawi.com

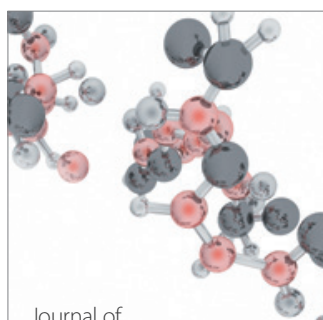

Analytical Methods

in Chemistry

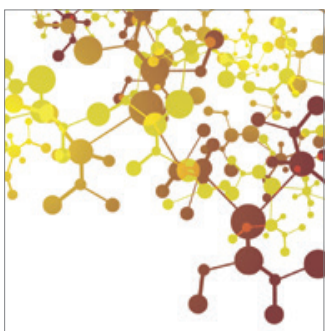

Journal of

Applied Chemistry

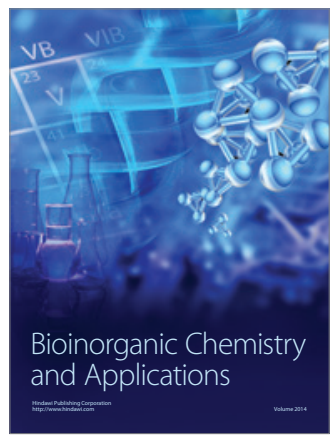

Inorganic Chemistry
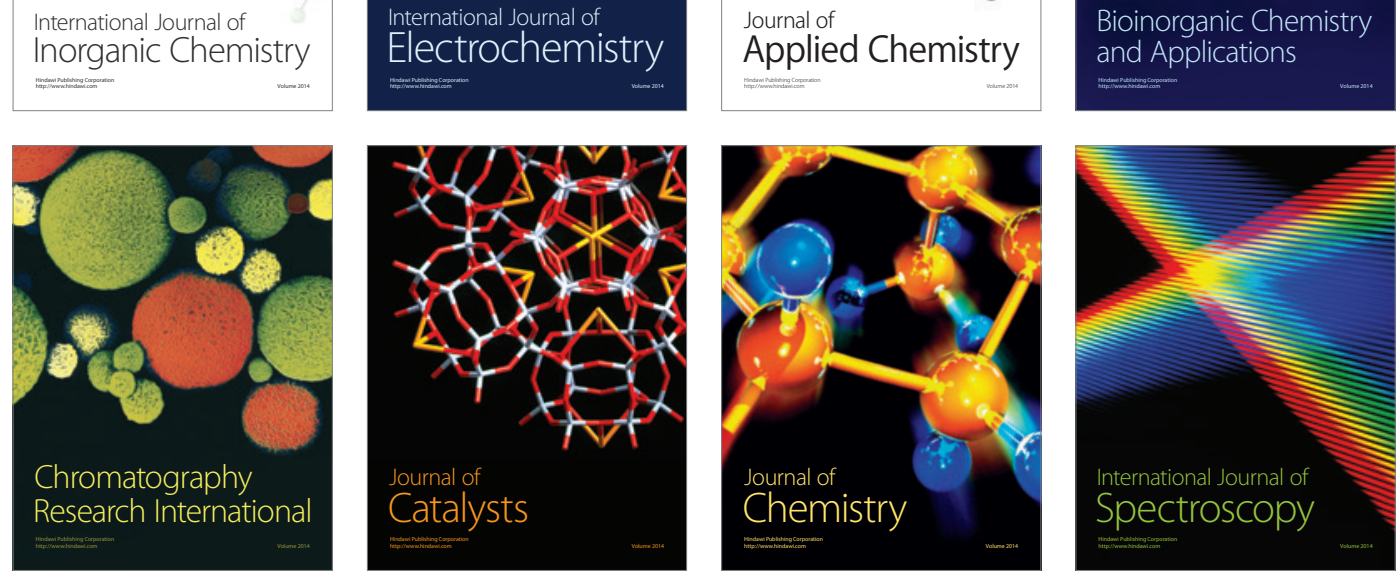